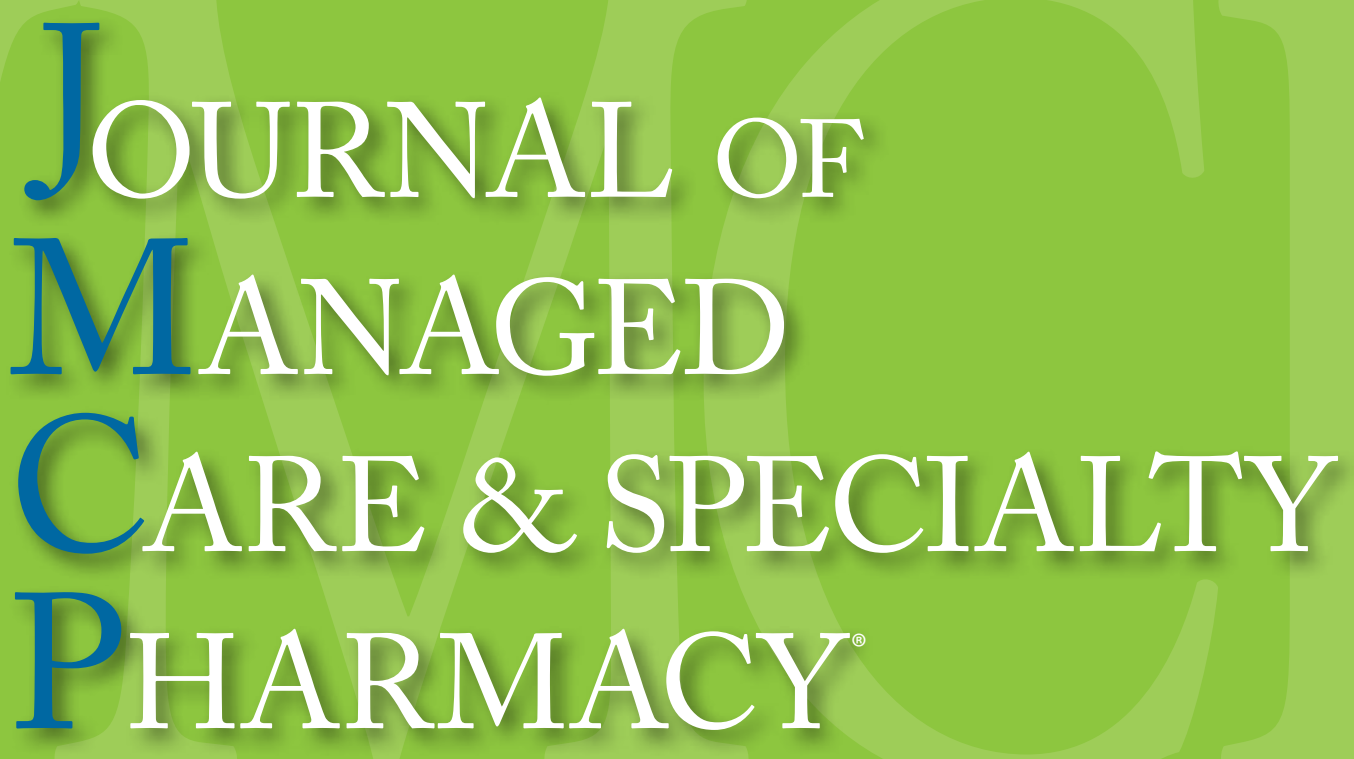

Supplement $\square$ Volume 23 — Number 4-a $\approx$ April 2017

\title{
Focus on Hyperkalemia Management: Expert Consensus and Economic Impacts
}

Paula Alvarez, RPh, MBA, MPH; Melanie Brenner, PharmD, BCPS; Javed Butler, MD; Carolyn Farnum, BS; Anne Kangethe, PharmD, MPH, PhD; Richard Lafayette, MD; Maria Lopes, MD; Todd C. Lord, PharmD;

Nina Oestreicher, PhD, MS; Macaulay Onuigbo, MD, MSc, FWACP, FASN, MBA;

W. Frank Peacock, MD, FACEP, FACC; Bertram Pitt, MD; Michael Polson, PharmD, MS;

Zubaid Rafique, MD, FACEP; Lindsay Speicher, JD; and Matthew R. Weir, MD 


\section{MCP}

Publisher

Susan A. Cantrell, RPh, CAE

Chief Executive Officer

Academy of Managed Care Pharmacy

\section{Editor-in-Chief}

Laura E. Happe, PharmD, MPH

864.938.3837; lhappe@jmcp.org

\section{Assistant Editor}

Robert P. Navarro, PharmD

University of Florida College of Pharmacy

Gainesville, FL

\section{Assistant Editor}

Karen L. Rascati, PhD

University of Texas College of Pharmacy

Austin, TX

\section{Assistant Editor}

Karen M. Stockl, PharmD

OptumRx, Irvine, CA

\section{Managing Editor}

Jennifer A. Booker

703.317.0725; jmcpreview@amcp.org

\section{Production Editor}

Carol Blumentritt

602.616.7249; cblumentritt@amcp.org

\section{Graphic Designer}

Margie C. Hunter

703.297.9319; mhunter@amcp.org

\section{Account Manager}

Grant Menard, American Medical Communications, Inc. 267.614.6809, GMenard@americanmedicalcomm.com

This supplement to the Journal of Managed Care \& Specialty Pharmacy (ISSN 2376-0540) is a publication of the Academy of Managed Care Pharmacy, 675 North Washington St., Suite 220, Alexandria, VA 22314; 703.684.2600

Copyright $(\odot)$ 2017, Academy of Managed Care Pharmacy. All rights reserved. No part of this publication may be reproduced or transmitted in any form or by any means, electronic or mechanical, without written permission from the Academy of Managed Care Pharmacy.

POSTMASTER: Send address changes to JMCP,

675 North Washington St., Suite 220, Alexandria, VA 22314

\section{Supplement Policy Statement}

\section{Standards for Supplements to the}

Journal of Managed Care \& Specialty Pharmacy Supplements to the Journal of Managed Care \& Specialty Pharmacy (JMCP) are intended to support medical education and research in areas of clinical practice, health care quality improvement, or efficient administration and delivery of health benefits. The following standards are applied to all JMCP supplements to ensure quality and assist readers in evaluating potential bias and determining alternate explanations for findings and results.

1. Disclose the principal sources of funding in a manner that permits easy recognition by the reader.

2. Disclose the existence of all potential conflicts of interest among supplement contributors, including financial or personal bias.

3. Describe all drugs by generic name unless the use of the brand name is necessary to reduce the opportunity for confusion among readers.

4. Identify any off-label (unapproved) use by drug name and specific off-label indication.

5. Strive to report subjects of current interest to managed care pharmacists and other managed care professionals.

6. Seek and publish content that does not duplicate content in the Journal of Managed Care \& Specialty Pharmacy.

7. Subject all supplements to expert peer review.

\section{AUTHORS}

Paula Alvarez, RPh, MBA, MPH

Director, Managed Care Health Outcomes

Relypsa, Redwood City, CA

Melanie Brenner, PharmD, BCPS

Health Economics and Outcome Research

Relypsa, Redwood City, CA

Javed Butler, MD

Co-Director, Heart Institute, and Chief, Division of Cardiology

Stony Brook University, Stony Brook, NY

Carolyn Farnum, BS

Senior Market Research Manager

Magellan Rx Management, Newport, RI

Anne Kangethe, PharmD, MPH, PhD

Manager, Health Economics Outcomes Research

Magellan Rx Management, Newport, RI

Richard Lafayette, MD

Professor of Medicine (Nephrology)

Stanford University Medical Center, Stanford, CA

Maria Lopes, MD

Chief Medical Officer

Magellan Rx Management, Newport, RI

Todd C. Lord, PharmD

Vice President, Magellan Method

Magellan Rx Management, Newport, RI

Nina Oestreicher, PhD, MS

Executive Director, Epidemiology, HEOR \& Observational Research

Relypsa, Redwood City, CA

University of California, San Francisco

Department of Clinical Pharmacy, San Francisco, CA

Macaulay Onuigbo, MD, MSc, FWACP, FASN, MBA

Nephrologist, Mayo Clinic Health System, Eau Claire, WI

Associate Professor, Mayo Clinic, Rochester, MN

W. Frank Peacock, MD, FACEP, FACC

Professor of Emergency Medicine, and Associate Chair

and Research Director for Emergency Medicine

Baylor College of Medicine, Texas Medical Center, Houston, TX

Bertram Pitt, MD

Professor of Internal Medicine Emeritus

University of Michigan School of Medicine, Ann Arbor, MI

Michael Polson, PharmD, MS

Senior Director, Health Economics Outcomes Research

Magellan Rx Management, Newport, RI

Zubaid Rafique, MD, FACEP

Assistant Professor Emergency Medicine

Baylor College of Medicine, Texas Medical Center, Houston, TX

Lindsay Speicher, JD

Senior Managed Market Specialist

Magellan Rx Management, Newport, RI

Matthew R. Weir, MD

Director, Division of Nephrology, Department of Medicine

University of Maryland School of Medicine, Baltimore, MD 


\section{Table of Contents}

\section{Focus on Hyperkalemia Management: Expert Consensus and Economic Impacts}

Paula Alvarez, RPh, MBA, MPH; Melanie Brenner, PharmD, BCPS; Javed Butler, MD; Carolyn Farnum, BS; Anne Kangethe, PharmD, MPH, PhD; Richard Lafayette, MD; Maria Lopes, MD; Todd C. Lord, PharmD; Nina Oestreicher, PhD, MS; Macaulay Onuigbo, MD, MSc, FWACP, FASN, MBA;

W. Frank Peacock, MD, FACEP, FACC; Bertram Pitt, MD; Michael Polson, PharmD, MS; Zubaid Rafique, MD, FACEP; Lindsay Speicher, JD; and Matthew R. Weir, MD

S10 Expert Panel Recommendations for the Identification and Management of Hyperkalemia and Role of Patiromer in Patients with Chronic Kidney Disease and Heart Failure Zubaid Rafique, MD, FACEP; Matthew R. Weir, MD; Macaulay Onuigbo, MD, MSc, FWACP, FASN, MBA; Bertram Pitt, MD; Richard Lafayette, MD; Javed Butler, MD; Maria Lopes, MD; Carolyn Farnum, $B S$; and W. Frank Peacock, MD, FACEP, FACC

\section{Disclosures}

This supplement was funded by Relypsa and developed by Magellan Rx Management. Polson, Lord, Kangethe, Speicher, Lopes, and Farnum are full-time employees of Magellan Rx Management. Brenner, Oestreicher, and Alvarez are full-time employees of Relypsa. The retrospective cohort study included in this supplement was conducted by Magellan Rx Management and funded by Relypsa. 


\title{
Expert Panel Recommendations for the Identification and Management of Hyperkalemia and Role of Patiromer in Patients with Chronic Kidney Disease and Heart Failure
}

\author{
Zubaid Rafique, MD, FACEP; Matthew R. Weir, MD; Macaulay Onuigbo, MD, MSc, FWACP, FASN, MBA; \\ Bertram Pitt, MD; Richard Lafayette, MD; Javed Butler, MD; Maria Lopes, MD; Carolyn Farnum, BS; \\ and W. Frank Peacock, MD, FACEP, FACC
}

\begin{abstract}
SUMMARY
Virtual panel meetings were conducted among 7 physicians, all of whom are independent experts, including 3 nephrologists, 2 cardiologists, and 2 emergency medicine physicians (the panel). The panel met with the purpose of discussing the current treatment landscape, treatment challenges, economic impact, and gaps in care for patients with hyperkalemia that is associated with heart failure and chronic kidney disease. The stated goal of the panel discussion was to develop practical solutions in the identification and management of hyperkalemia in this patient population.

The panel noted that hyperkalemia is a serious condition that can lead to life-threatening complications, yet the treatment paradigm for hyperkalemia has remained without major advances for approximately 50 years, until the approval of patiromer.

A number of issues still exist in the management of this patient population, including the lack of uniform treatment guidelines and consensus regarding the approach to treatment. As part of its effort, the panel developed an algorithm, the Proposed Diagnostic Algorithm for Hyperkalemia Treatment in the Acute Care Setting/Chronic Care. The panel agreed that patiromer appears to be a viable option for the management of hyperkalemia in patients with chronic kidney disease and/or heart failure and in patients who experience chronic hyperkalemia.
\end{abstract}

J Manag Care Spec Pharm. 2017;23(4-a):S10-S19

Copyright $\odot 2017$, Academy of Managed Care Pharmacy. All rights reserved.

$\mathrm{H}$ yperkalemia is a life-threatening condition that can present acutely or chronically and is characterized by elevated serum potassium levels greater than 5.0 or $5.5 \mathrm{mEq} / \mathrm{L}^{1,2}$ Severe hyperkalemia is defined as having a serum potassium level greater than $6.0 \mathrm{mEq} / \mathrm{L} .{ }^{2}$ Hyperkalemia is associated with serious medical conditions such as cardiac arrhythmias, ventricular fibrillation, and sudden cardiac death. ${ }^{1}$ Hyperkalemia can be the result of various acute and chronic conditions that affect potassium homeostasis and commonly occurs in patients with chronic kidney disease (CKD), heart failure (HF), and diabetes mellitus (DM) ${ }^{2,3}$ Even when treated rapidly and appropriately, mortality for patients with severe hyperkalemia may be greater than $30 \%{ }^{3}$

\section{Methods for Creation of this Document}

Virtual panel meetings were conducted among a total of 7 physicians, all of whom are independent experts, including 3 nephrologists, 2 cardiologists, and 2 emergency medicine physicians (the panel). The panel met with the purpose of discussing the current treatment landscape, treatment challenges, economic impact, and gaps in care for patients with hyperkalemia that is associated with HF and CKD. The stated goal of the panel discussion was to develop practical solutions in the identification and management of hyperkalemia in this patient population. One large challenge in the treatment of this condition is that there is a lack of consensus regarding its management, particularly in the acute and chronic settings. This is problematic, as the treatment of this condition is costly, and wide variability among treatment approaches has the potential to result in unnecessary increases in treatment costs. The panel explored the role of traditional management strategies and pipeline and recently introduced treatments such as patiromer (Veltassa, Relypsa) in the treatment of hyperkalemia in patients with HF and CKD. Resources that may be of use to providers in the treatment of this patient population were also discussed.

\section{Epidemiology}

Patients who are at the highest risk of hyperkalemia are those with CKD stages 3-4, DM, HF, and any combination of these conditions, as well as patients who are being treated with drugs that inhibit renal potassium excretion, such as reninangiotensin-aldosterone system (RAAS) inhibitors. ${ }^{2,4}$ In a study conducted by Latts et al. (2015), which evaluated the 5 -year prevalence of hyperkalemia in approximately 1.7 million patients, $47.6 \%$ of patients in stages 3 or 4 CKD with HF had at least 1 episode of hyperkalemia compared with $8.5 \%$ of patients in the comparison group, which was composed of patients who did not have CKD stage 2 or higher, end-stage renal disease (ESRD), HF, or DM. ${ }^{4}$ Overall, of the $15.8 \%$ of patients who experienced at least 1 hyperkalemia event, 9.8\% had at least 1 mild hyperkalemia event and $6.1 \%$ had moderate/ severe events. ${ }^{4}$ Hyperkalemia was classified as mild ( $\mathrm{K}^{+} 5.1$ to $5.4 \mathrm{mEq} / \mathrm{L})$ or moderate/severe $\left(\mathrm{K}^{+} \geq 5.5 \mathrm{mEq} / \mathrm{L}\right)$ based on the highest measured value. ${ }^{4}$ Additionally, $8.5 \%$ of individuals in the control group experienced a hyperkalemia event compared to $23.5 \%$ of patients with HF, $29.5 \%$ with CKD stages $3-4$, and $47.6 \%$ with HF and CKD stages $3-4 .^{4}$

The prevalence of hyperkalemia was generally higher in patients 65 years of age and older than in individuals with similar comorbidities who were younger than 65 years of age. ${ }^{4}$ In addition, patients with DM, HF, CKD stages 3-4, and combinations of these conditions were 2.5 to 5.6 times more likely to experience hyperkalemia versus the cohort without any of these conditions. ${ }^{4}$ The authors of the study concluded that as medical comorbidity increases, either through declining renal function or through the development of other concomitant conditions, the prevalence of hyperkalemia also increases. 


\begin{tabular}{|c|c|c|c|}
\hline & $\begin{array}{c}\text { All } \\
\text { ED Visits }\end{array}$ & $\begin{array}{l}\text { ED Visits } \\
\text { with } \\
\text { Admission } \\
\text { to the Same } \\
\text { Hospital }\end{array}$ & $\begin{array}{l}\text { Discharged } \\
\text { from the ED }\end{array}$ \\
\hline Total number of visits & 76,028 & 35,166 & 40,862 \\
\hline $\begin{array}{l}\text { ED visits with admission to the } \\
\text { same hospital, } \mathrm{n}(\%)\end{array}$ & $\begin{array}{l}35,166 \\
(46.25) \\
\end{array}$ & $\begin{array}{l}35,166 \\
(100.00) \\
\end{array}$ & $a$ \\
\hline Died during ED visit, n (\%) & $\begin{array}{c}168 \\
(0.41) \\
\end{array}$ & N/A & $\begin{array}{c}168 \\
(0.41) \\
\end{array}$ \\
\hline Died during hospital stay, n (\%) & $\begin{array}{c}482 \\
(1.37) \\
\end{array}$ & $\begin{array}{c}482 \\
(1.37) \\
\end{array}$ & N/A \\
\hline \multicolumn{4}{|c|}{$\begin{array}{l}\text { aStatistics based on estimates with a relative standard error (standard errorl } \\
\text { weighted estimate) greater than } 0.30 \text { or with standard error =0 in the nationwide } \\
\text { statistics (NIS, NEDS, and KID) are not reliable. These statistics are suppressed. } \\
\text { ED=emergency department; ICD-9-CM=International Classification of Diseases, } \\
\text { Ninth Revision, Clinical Modification; KID=Kids' Inpatient Database; N/A=not } \\
\text { applicable; NEDS = Nationwide Emergency Department Sample; NIS= National } \\
\text { Inpatient Sample. }\end{array}$} \\
\hline
\end{tabular}

Although the incidence and prevalence of hyperkalemia in the general population have not been extensively studied, some studies conducted among hospitalized patients have estimated the prevalence to be between 1 and 10 per 100 patients. $^{5}$ In addition, some retrospective analyses have reported that the prevalence of hyperkalemia is between $2.5 \%$ and $3.2 \%$ in populations with diverse risk factors, although the actual prevalence is dependent upon the patient population being studied and the serum potassium threshold used to determine hyperkalemia. ${ }^{2,6}$ Nonetheless, the presence of CKD is consistently associated with hyperkalemia.

\section{Economic Impact}

In the United States, hyperkalemia represents a considerable economic, societal, and health system burden. The financial burden of the condition is largely a result of the costs associated with emergency department (ED) visits, inpatient stays, pharmacological treatments, and disease-related mortality. Additionally, there are considerable costs associated with adverse outcomes that occur as a result of suboptimal use of RAAS inhibitor therapy, which may be due to discontinuation or down-titration of the treatment based on concerns about hyperkalemia.

ED visits for hyperkalemia or hyperpotassemia were examined using discharge data from the Nationwide Emergency Department Sample (NEDS), Healthcare Cost and Utilization Project (HCUP), and Agency for Healthcare Research and Quality (AHRQ). Data indicated that there were 76,028 visits to the ED with a primary diagnosis of hyperkalemia (hyperpotassemia; International Classification of Diseases, Ninth Revision,

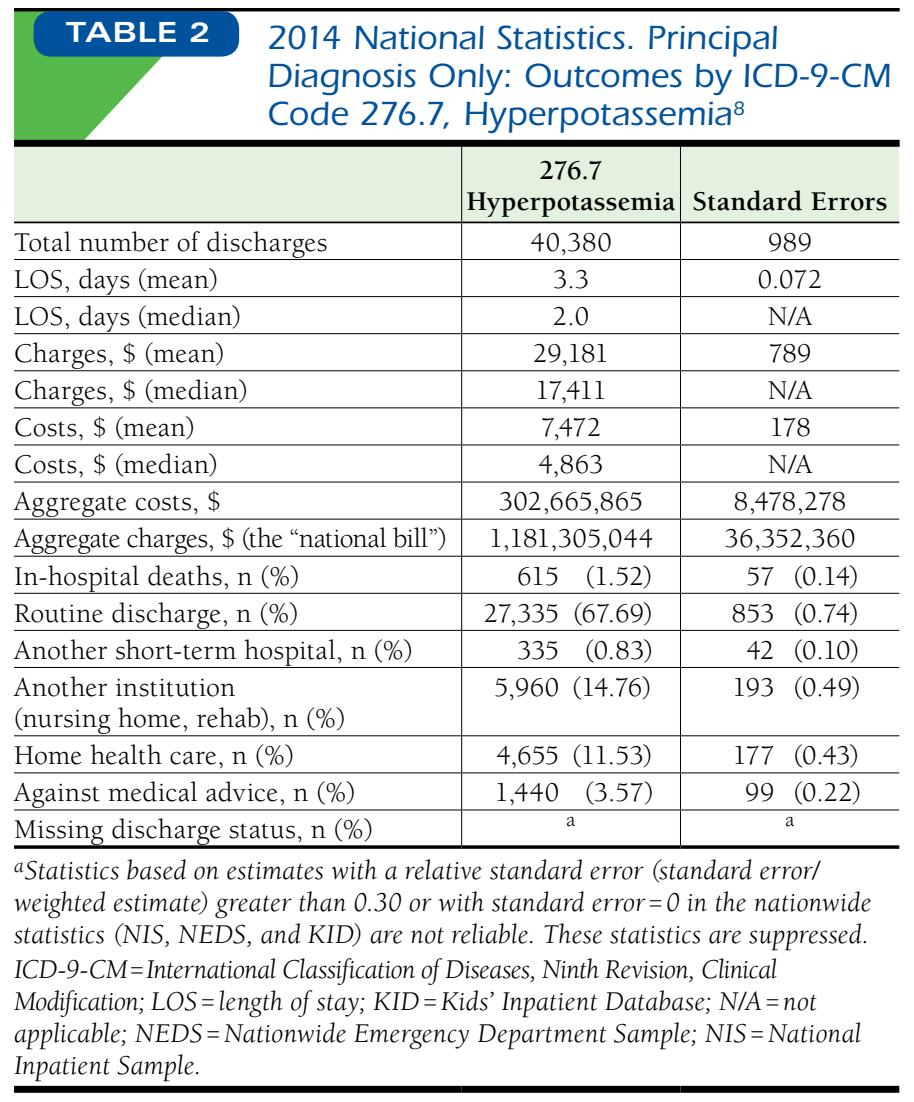

Clinical Modification [ICD-9-CM] code 276.7) in 2014. Of these visits, 35,166 were ED visits with admission to the same hospital, and 40,862 represented discharges from the ED (Table 1). ${ }^{7}$ In addition, regional cost differences for hyperkalemia admissions were examined using discharge data from the National Inpatient Sample (NIS), HCUP, and AHRQ. ${ }^{8}$ For the patients admitted, there was an average length of stay of 3.3 days, with an average charge of $\$ 29,181$ per stay (Table 2). ${ }^{8}$ These data suggest that hyperkalemia is associated with increased ED visits and hospitalizations, both of which result in increased costs. Additionally, hyperkalemia predominantly affects the Medicare population compared to patients with other types of insurance (Table 3). ${ }^{8}$ National and state statistics differences by payer type were examined using discharge data from the NIS, HCUP, and AHRQ. ${ }^{8}$ These data from 2014 indicated that where hyperkalemia was listed as the primary diagnosis, $66.42 \%$ of the patients were Medicare beneficiaries, and over $\$ 821$ million of the national bill was accounted for by these individuals' costs. ${ }^{8}$

A study conducted by Jain et al. (2012) further emphasized that hospitalization rates and mortality were higher in patients with hyperkalemia and cardiovascular disease (CVD) than in those without CVD. ${ }^{9}$ In this retrospective analysis that evaluated all-cause mortality in patients with CVD who were receiving treatment with antihypertensive drugs, patients who 


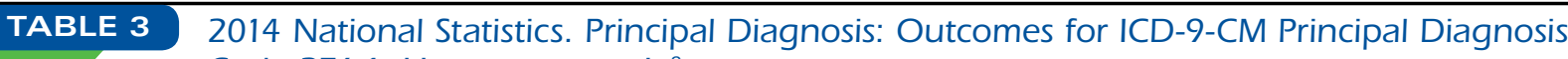
Code 276.1, Hyperpotassemia ${ }^{8}$

\begin{tabular}{|c|c|c|c|c|c|}
\hline & All Payers Combined & Medicare & Medicaid & Private Insurance & Uninsured \\
\hline Total number of discharges, $\mathrm{n}(\%)$ & $40,380(100.00)$ & $26,820(66.42)$ & $6,795(16.83)$ & $4,510(11.17)$ & $1,585(3.93)$ \\
\hline LOS, days (mean) & 3.3 & 3.5 & 3.0 & 2.9 & 2.5 \\
\hline LOS, days (median) & 2.0 & 2.0 & 2.0 & 2.0 & 1.0 \\
\hline Charges, \$ (mean) & 29,181 & 30,543 & 27,181 & 25,432 & 21,536 \\
\hline Charges, \$ (median) & 17,411 & 18,167 & 16,925 & 15,719 & 12,710 \\
\hline Aggregate charges, \$ (the "national bill") & $1,181,305,044$ & $821,122,977$ & $184,893,947$ & $115,314,419$ & $34,134,190$ \\
\hline
\end{tabular}

ICD-9-CM = International Classification of Diseases, Ninth Revision, Clinical Modification; LOS=length of stay.

had hyperkalemia demonstrated higher rates of hospitalization compared to those with normokalemia (7.80\% vs. $5.04 \%$, respectively; $P=0.0001)$ and higher mortality rates $(6.25 \%$ vs. $2.92 \%$, respectively; $P=0.0001) .{ }^{9}$

In a retrospective analysis performed by Einhorn et al. (2009), researchers evaluated the occurrence of hyperkalemia among 245,808 Veterans Affairs patients with and without CKD in the ambulatory and hospital settings. ${ }^{2}$ The results of the analysis indicated that among patients receiving RAAS inhibitors, specifically angiotensin-converting enzyme (ACE) inhibitors or angiotensin-II receptor blockers (ARBs), hyperkalemia occurred at a higher rate in patients with CKD than in those without (7.67 vs. 2.30 per 100 patient-months; $P<0.001)^{2}$

ACE inhibitors and ARBs are commonly used in the treatment of patients with CKD, DM, and/or HF; however, due to concerns over the development of hyperkalemia, these RAAS inhibitors may be prescribed at suboptimal doses or not at all, which may be detrimental to long-term outcomes and contribute to increased medical expenditures. ${ }^{10,11}$ A budget impact model was developed to estimate the potential benefits of losartan by modeling a patient cohort similar to the treatment groups included in the RENAAL (Reduction of Endpoints in NIDDM with the Angiotensin II Antagonist Losartan) trial. ${ }^{11}$ The model was developed to simulate the 10 -year cost savings and outcome improvements of renoprotective therapy, specifically losartan, for a cohort of privately insured patients with diabetes and advanced CKD, compared to no treatment. ${ }^{11}$ For the best-case scenario, which assumed a patient cohort that matched the patient population observed in the RENAAL trial, the estimated annual cost savings were $\$ 10,990$ per patient after 10 years of treatment with losartan. ${ }^{11}$ For the conservative scenario, which assumed a patient cohort of less acutely ill patients, the estimated annual cost savings were $\$ 5,659$ per patient by year 10 among patients treated with losartan. ${ }^{11}$

\section{Current Approaches to Treatment and Gaps in Care}

The panel indicated that there are no clear, specific, standardized guidelines for the management of hyperkalemia in patients with CKD and/or HF, which is problematic given that hyperkalemia can often be a life-threatening condition. The panel noted that the approach to treatment can be highly variable and may be affected by a variety of factors. For example, nephrologists and cardiologists stated that if a patient has a serum potassium level of $5.8 \mathrm{mEq} / \mathrm{L}$, the provider may decide not to treat immediately but instead wait a few weeks, repeat the test, and potentially initiate treatment based on the subsequent lab results. These panel participants further explained that their colleagues who treat a patient with the same potassium level may decide to utilize a different approach and initiate treatment immediately.

Physicians on the panel who work in the ED indicated that elevated potassium levels typically result in immediate treatment, followed by a referral based on the specific level. If the potassium level is $6 \mathrm{mEq} / \mathrm{L}$ or greater, the patient will receive an emergency referral to nephrology for dialysis; however, if the level is less than $6 \mathrm{mEq} / \mathrm{L}$, non-ESRD patients are typically discharged home for outpatient follow-up with their primary care physician. The panel also indicated that internal medicine physicians may want to manage hyperkalemia without referral to a specialist. The panel discussions revealed that approaches to treatment may depend on the site of care, physician specialty, and comfort level of the physician in treating hyperkalemia in patients with baseline renal dysfunction and medical comorbidities.

Among the medications that can lead to or worsen hyperkalemia, RAAS inhibitors are major contributors. This is problematic as these medications have been shown to reduce morbidity and mortality in patients with CKD, DM, and CVD. ${ }^{12-14}$ RAAS inhibitors, irrespective of dose but especially at higher doses, can cause hyperkalemia, thereby limiting their use at optimal doses for cardiorenal protection. ${ }^{15}$ In patients with hypertension who do not have risk factors for hyperkalemia, treatment with RAAS inhibitor monotherapy is associated with an incidence of hyperkalemia below 2\% but increases to $5 \%$ when dual RAAS inhibition is used. ${ }^{16}$ The incidence of hyperkalemia is even greater in patients with HF or CKD and ranges from $5 \%$ to $10 \%{ }^{16}$

In a study performed by Epstein et al. (2015), patients receiving RAAS inhibitors who had hyperkalemia were subject 


\section{Expert Panel Recommendations for the Identification and Management of Hyperkalemia and Role of Patiromer in Patients with Chronic Kidney Disease and Heart Failure}

\begin{tabular}{|c|c|c|c|c|}
\hline $\begin{array}{l}\text { Treatment } \\
\text { Strategy }\end{array}$ & $\begin{array}{l}\text { Mechanism } \\
\text { of Action }\end{array}$ & Advantages & Limitations & Clinical Setting \\
\hline $\begin{array}{l}\text { Beta2-adrenergic } \\
\text { receptor agonists }\end{array}$ & $\begin{array}{l}\mathrm{K}^{+} \text {redistribution into } \\
\text { the intracellular space }\end{array}$ & $\begin{array}{l}\text { Onset of action ( } \sim 30 \text { minutes) } \\
\text { Effect is independent of insulin } \\
\text { and aldosterone }\end{array}$ & $\begin{array}{l}\text { Short duration, inconsistent effect ( } 2-4 \text { hours) } \\
\text { Does not reduce total } \mathrm{K}^{+} \text {levels } \\
\text { Use with caution in ischemic heart disease } \\
\text { (risk of tachycardia) }\end{array}$ & Emergency treatment \\
\hline Insulin glucose & $\begin{array}{l}\mathrm{K}^{+} \text {redistribution into } \\
\text { the intracellular space }\end{array}$ & $\begin{array}{l}\text { Onset of action within } 30 \text { minutes } \\
\text { Effects last } 4-6 \text { hours }\end{array}$ & $\begin{array}{l}\text { Risk of hypoglycemia } \\
\text { Does not reduce total } \mathrm{K}^{+} \text {levels }\end{array}$ & Emergency treatment \\
\hline $\begin{array}{l}\text { Calcium } \\
\text { gluconate }\end{array}$ & $\begin{array}{l}\text { Membrane } \\
\text { stabilization }\end{array}$ & $\begin{array}{l}\text { Onset of action in } 1-3 \text { minutes } \\
\text { Efficacy can be monitored with } \\
\text { ECG and dose can be repeated if } \\
\text { no changes observed }\end{array}$ & $\begin{array}{l}\text { Short duration of effect ( } 30-60 \text { minutes) } \\
\text { Serum } \mathrm{K}^{+} \text {level is unaffected } \\
\text { Avoid in patients receiving digoxin } \\
\text { (risk of digoxin toxicity) } \\
\text { Risk of hypercalcemia }\end{array}$ & Emergency treatment \\
\hline $\begin{array}{l}\text { Sodium } \\
\text { bicarbonate }\end{array}$ & $\begin{array}{l}\mathrm{K}^{+} \text {redistribution into } \\
\text { the intracellular space } \\
\text { When administered } \\
\text { by infusion over } 4-6 \\
\text { hours, it may enhance } \\
\text { urinary } \mathrm{K}^{+} \text {excretion }\end{array}$ & $\begin{array}{l}\text { Evidence is mixed } \\
\text { Recommended when acidosis is } \\
\text { the cause of hyperkalemia }\end{array}$ & $\begin{array}{l}\text { No immediate reductions in serum } \mathrm{K}^{+} \text {; } \\
\text { effects may be observed after } 4-6 \text { hours } \\
\text { Risk of metabolic alkalosis and volume } \\
\text { overload } \\
\text { Longer follow-up data were not available } \\
\text { from RCTs }\end{array}$ & $\begin{array}{l}\text { Intermediate/nonemergent/ } \\
\text { subacute care setting } \\
\text { Adjunct treatment in emergent } \\
\text { setting once emergency } \\
\text { treatments have been started }\end{array}$ \\
\hline Diuretics & $\mathrm{K}^{+}$elimination & $\begin{array}{l}\text { Onset of action depends on start } \\
\text { of diuresis } \\
\text { Beneficial in patients with } \\
\text { volume expansion }\end{array}$ & $\begin{array}{l}\text { Efficacy depends on residual renal } \\
\text { function (until diuresis is present) } \\
\text { Increased risk for gout and volume depletion } \\
\text { May produce volume contraction, } \\
\text { decreased distal nephron flow, worsening } \\
\text { of kidney function, and reduced } \mathrm{K}^{+} \\
\text {excretion }\end{array}$ & $\begin{array}{l}\text { Intermediate/nonemergent/ } \\
\text { subacute care setting (loop } \\
\text { diuretics) } \\
\text { Adjunct treatment in emergent } \\
\text { setting once emergency } \\
\text { treatments have been started } \\
\text { Chronic/maintenance treatment } \\
\text { (loop or thiazide diuretics) }\end{array}$ \\
\hline $\begin{array}{l}\text { Dialysis } \\
\text { (hemodialysis, } \\
\text { peritoneal } \\
\text { dialysis) }\end{array}$ & $\mathrm{K}^{+}$elimination & $\begin{array}{l}\text { Onset of action within minutes } \\
\text { Effects lasting until end of } \\
\text { dialysis or longer }\end{array}$ & $\begin{array}{l}\text { Limitations and complications inherent to } \\
\text { each dialysis modality (i.e., arrhythmias } \\
\text { with hemodialysis) }\end{array}$ & $\begin{array}{l}\text { Intermediate/nonemergent/ } \\
\text { subacute care setting } \\
\text { Adjunct treatment in emergent } \\
\text { setting once emergency } \\
\text { treatments have been started } \\
\text { Chronic/maintenance treatment }\end{array}$ \\
\hline $\begin{array}{l}\text { Sodium } \\
\text { polystyrene } \\
\text { sulfonate }\end{array}$ & $\mathrm{K}^{+}$elimination & $\begin{array}{l}\text { Efficacy of } 6.9 \text { days } \\
\text { Effects may last } 4-6 \text { hours longer } \\
\text { depending on ongoing potassium } \\
\text { intake or cellular redistribution }\end{array}$ & $\begin{array}{l}\text { No consistent evidence of efficacy } \\
\text { Serious GI AEs reported, including fatal } \\
\text { cases of intestinal necrosis } \\
\text { Caution with sodium loads in patients } \\
\text { with CHF, hypertension, or edema }\end{array}$ & $\begin{array}{l}\text { Adjunct treatment in emergent } \\
\text { setting once emergency } \\
\text { treatments have been started } \\
\text { Chronic/maintenance treatment }\end{array}$ \\
\hline $\begin{array}{l}\text { Low-potassium } \\
\text { diet }\end{array}$ & $\begin{array}{l}\text { Reducing potassium } \\
\text { intake }\end{array}$ & $\begin{array}{l}\text { May improve metabolic acidosis } \\
\text { in CKD }\end{array}$ & $\begin{array}{l}\text { Difficult to adhere to a low-potassium diet } \\
\text { Limiting } \mathrm{K}^{+} \text {rich foods can cause } \\
\text { constipation } \\
\text { Contradicts the DASH diet; may worsen } \\
\text { chronic hypertension }\end{array}$ & Chronic/maintenance treatment \\
\hline $\begin{array}{l}\text { Discontinuation/ } \\
\text { dose reduction of } \\
\text { RAAS inhibitors }\end{array}$ & $\begin{array}{l}\text { Identification and } \\
\text { interruption of } \\
\text { hyperkalemia- } \\
\text { inducing medications }\end{array}$ & $\begin{array}{l}\text { Prevention of recurrent } \\
\text { hyperkalemia events }\end{array}$ & $\begin{array}{l}\text { Stopping or suboptimal utilization of } \\
\text { renal/cardioprotective RAAS inhibitor } \\
\text { therapy }\end{array}$ & Chronic/maintenance treatment \\
\hline $\begin{array}{l}\text { Patiromer for oral } \\
\text { suspension }\end{array}$ & $\mathrm{K}^{+}$elimination & $\begin{array}{l}\text { Onset of action } 7 \text { hours } \\
\text { Management of hyperkalemia }\end{array}$ & $\begin{array}{l}\text { Can take } 3 \text { hours before or after any } \\
\text { medication } \\
\text { Patiromer decreased the systemic } \\
\text { exposure of coadministered ciprofloxacin, } \\
\text { metformin, and levothyroxine. However, } \\
\text { there was no interaction when patiromer } \\
\text { and these drugs were taken } 3 \text { hours } \\
\text { apart } 30 \\
\text { No data to date to show efficacy in the } \\
\text { acute setting }\end{array}$ & $\begin{array}{l}\text { Adjunct treatment in emergent } \\
\text { setting once emergency } \\
\text { treatments have been started } \\
\text { Chronic/maintenance treatment }\end{array}$ \\
\hline
\end{tabular}

$A E=$ adverse event $; C H F=$ congestive heart failure; $C K D=$ chronic kidney disease; DASH = Dietary Approaches to Stop Hypertension; ECG = electrocardiographic; $G I=$ gastrointestinal $; R A A S=$ renin-angiotensin-aldosterone system; $R C T=$ randomized controlled trial . 
played a role in the subacute management of hyperkalemia as adjunct therapies, once emergent treatments have been started.

In the chronic management setting of hyperkalemia, it is important to identify any underlying causes for an episode of hyperkalemia and to manage these factors/causes on an ongoing basis. Dietary potassium restriction and oral administration of sodium bicarbonate and loop diuretics can be utilized. SPS will occasionally be given in the chronic setting, but due to the poor taste, profound diarrhea, associated side effects, and salt load, patients may be nonadherent to treatment. In patients with ESRD, longer dialysis sessions, reduced potassium in the dialysate, and dietary restriction can be utilized. With regard to the identification of any underlying causes, the drugs listed in Table 5 have been known to cause hyperkalemia. ${ }^{20}$

The panel commented that current options to manage hyperkalemia on a chronic basis are limited, and robust evidence supporting their efficacy and safety in the outpatient setting is lacking. The panel recommended that more clinical trials be conducted. Before the approval of patiromer in 2015 , SPS, an ion-exchange resin designed to bind potassium in exchange for sodium in the colon, was the only approved treatment for hyperkalemia. ${ }^{21}$ SPS was approved by the U.S. Food and Drug Administration (FDA) in 1958, 4 years before the passing of the Kefauver-Harris Drug Amendment, which required that drug manufacturers prove the safety and efficacy of drugs. ${ }^{21,22}$

More recently, Lepage et al. (2015) conducted a small randomized controlled trial (RCT) in 33 patients to evaluate the efficacy of SPS in patients with CKD and mild hyperkalemia. ${ }^{23}$ Patients were randomly assigned to receive either placebo or 30 grams of SPS orally 1 time per day for 7 days. ${ }^{23}$ The primary outcome was the mean difference of serum potassium levels between the day after the last dose of treatment and baseline. ${ }^{23}$ The results of the study indicated that the mean duration of treatment was 6.9 days and that SPS was superior to placebo in the reduction of serum potassium levels (mean difference between groups: $-1.04 \mathrm{mEq} / \mathrm{L}$; 95\% confidence interval, -1.37 to -0.71$).{ }^{23} \mathrm{~A}$ higher proportion of patients in the SPS group attained normokalemia at the end of their treatment compared with those in the placebo group, but the difference was not statistically significant $(73 \%$ vs. $38 \% ; P=0.07) .{ }^{23}$ There was a higher rate of electrolyte disturbances and gastrointestinal (GI) side effects in the SPS group, and SPS was considered superior to placebo in reducing serum potassium over 7 days in patients with mild hyperkalemia and CKD. ${ }^{23}$

The use of SPS is limited by its propensity to cause GI adverse events (AEs) (e.g., diarrhea, nausea, and vomiting) and other systemic toxicities, including sodium loading, hypomagnesemia, hypocalcemia, and colonic necrosis. ${ }^{24-27}$ Historically, SPS was administered with sorbitol, a laxative, because of the potential for constipation to develop and because of the ability of sorbitol to further increase potassium elimination; however, in 2009, the FDA issued a warning with regard to the concomitant use of SPS and sorbitol following reports of colonic necrosis and other serious GI AEs. ${ }^{28}$

The panel expressed the opinion that SPS is not the ideal drug to use in the treatment of hyperkalemia because of its unfavorable safety and efficacy profile, safety warning for colonic necrosis, poor tolerability, and unpalatable taste. These aforementioned factors present a challenge to patients and providers, and the approval of new agents could aid in the treatment of hyperkalemia. The panel also stated that physicians must carefully assess uncontrolled studies demonstrating benefit versus risk with SPS. Therefore, the panel recommended that all other treatment options be exhausted prior to using this potentially harmful therapy with little evidence of efficacy.

\section{The Role of Patiromer}

Until recently, treatment options for patients with chronic hyperkalemia have been limited to nonpharmacological interventions (e.g., low dietary potassium intake), loop diuretics with or without sodium bicarbonate, and/or dose adjustments or discontinuation of RAAS inhibitor therapies. Some physicians have even given fludrocortisone. These limited options are not optimal for most patients. Thus, there is an unmet need for a safe, efficacious, and well-tolerated chronic strategy to control hyperkalemia. Before the availability of patiromer, physicians generally considered the following management strategies:

- If diet alone could not control potassium, doses of diuretic medications were increased and bicarbonate replacement was considered; however, these treatments ultimately lose their effectiveness as patients lose kidney function.

- When RAAS inhibitor dose reduction did not achieve desired results, RAAS inhibitor therapy was eventually discontinued.

- Some physicians have even given fludrocortisone with its risk for hypertension and vascular injury.

On October 21, 2015, patiromer received FDA approval for the treatment of hyperkalemia. ${ }^{29}$ Patiromer is a polymer that exchanges calcium for potassium. ${ }^{30}$ It has been shown to lower and maintain serum potassium levels in patients with CKD who are receiving RAAS inhibitors. ${ }^{31}$ This treatment is not indicated to prevent hyperkalemia. ${ }^{30}$ Additionally, due to its delayed onset of action, patiromer is not intended for use as an emergency treatment for life-threatening hyperkalemia. ${ }^{30}$ Patiromer has the potential to bind to orally administered medications, which could reduce their absorption and effectiveness. ${ }^{30}$ As a result, it is recommended that other oral medications should be administered at least 3 hours before or 3 hours after patiromer. ${ }^{30}$ 
The 2 main clinical trials that contributed to the approval of patiromer were OPAL-HK and AMETHYST-DN. ${ }^{32,33}$ The multinational, single-blind, 2-phase OPAL-HK study evaluated the efficacy of patiromer in patients with CKD who were receiving RAAS inhibitors. ${ }^{32}$ In phase 1 , all participants received a starting dose of patiromer of 8.4 grams or 16.8 grams daily in 2 divided doses, depending on the severity of hyperkalemia, at baseline for 4 weeks. ${ }^{32}$ The results of the study demonstrated an average decrease in serum potassium concentration of 1.01 $\mathrm{mEq} / \mathrm{L}$, and $76 \%$ of patients had serum potassium levels within the target range of 3.8 to $\leq 5.1 \mathrm{mEq} / \mathrm{L}$ at the end of 4 weeks. ${ }^{32}$ In phase 2, the 8-week randomized withdrawal phase explored the effects of continuation of patiromer versus switching to placebo. ${ }^{32}$ The results of the phase 2 portion demonstrated that there was no change in potassium levels in participants who continued patiromer; however, for patients who switched to placebo, an average increase of $0.72 \mathrm{mEq} / \mathrm{L}$ in serum potassium levels over the first 4 weeks of the phase was observed. ${ }^{32}$ These results demonstrate the need for continuous treatment in this patient population and support the benefit of chronic use of patiromer to maintain safe potassium levels.

The 52-week, multi-center, open-label randomized AMETHYST-DN study evaluated the safety and efficacy of patiromer in hypertensive patients with DM or CKD. ${ }^{33}$ Patients were stratified according to baseline serum potassium levels and received 1 of 3 randomized starting doses ranging from $8.4 \mathrm{~g}$ to $33.6 \mathrm{~g}$ daily, administered in 2 divided doses. ${ }^{33}$ The doses were titrated to achieve and maintain serum potassium levels $\leq 5.0 \mathrm{mEq} / \mathrm{L} .{ }^{33}$ Observed decreases in serum potassium levels ranged from $0.35 \mathrm{mEq} / \mathrm{L}$ for patients on the lowest dose to $0.92 \mathrm{mEq} / \mathrm{L}$ for patients on the highest dose. ${ }^{33}$ There was no evidence of loss of efficacy over 1 year of treatment. ${ }^{33}$ The medication was also well tolerated with few dropouts. ${ }^{33}$

A third study, PEARL-HF, was a double-blind, randomized, placebo-controlled trial that was designed to assess the safety and efficacy of patiromer over 4 weeks in chronic HF patients who were candidates for spironolactone and had a serum potassium level between 4.3 and $5.1 \mathrm{mEq} / \mathrm{L} .{ }^{34}$ Enrolled patients must have also had a history of documented hyperkalemia resulting in discontinuation of an aldosterone antagonist, ACE inhibitor, ARB, or beta-blocker or CKD with an estimated glomerular filtration rate $<60 \mathrm{~mL} /$ minute. A mean decrease in serum potassium of $0.22 \mathrm{mEq} / \mathrm{L}$ from baseline was observed in the patiromer group compared to a mean increase of 0.23 $\mathrm{mEq} / \mathrm{L}$ from baseline in the placebo group. ${ }^{34}$ When spironolactone was administered concomitantly, treatment with patiromer prevented increases in potassium levels.

The panel indicated that, based on their clinical experience, they view patiromer as a viable treatment option for patients with hyperkalemia, especially in the chronic management setting, and that SPS and patiromer may be used as adjunct therapies once emergency treatments have been initiated.
However, more evidence is needed to support their use in the emergency setting. The panel also stated that an advantage of patiromer over SPS is the more favorable side effect profile, flavorless formulation, and use of calcium instead of sodium as the exchange ion, all of which have the potential to improve patient adherence. Based upon the 2\%-3\% incidence of hyperkalemia in the general population, 6.4 to 9.6 million people in the United States may qualify for treatment with patiromer. 9

\section{Panel Insights and Recommendations}

The panel noted that hyperkalemia is a serious condition that can lead to life-threatening complications, yet the treatment paradigm for hyperkalemia has remained without major advances for approximately 50 years until the approval of patiromer. ${ }^{35}$ Additionally, hyperkalemia can occur without clinical manifestations, which further complicates its diagnosis. ${ }^{36}$ Cardiac conduction defects and both depolarization and repolarization abnormalities can occur with hyperkalemia. ${ }^{37}$ Hyperkalemia can cause widening of the QRS complex, which increases pacing thresholds and can lead to failure to capture, and oversensing of, the spaced or spontaneous T-wave by implantable cardioverter-defibrillators, which can result in inappropriate shocks. ${ }^{38}$ Finally, hyperkalemia has caused electrocardiographic (ECG) changes that were mistaken for malfunction of pacemakers and implantable cardioverterdefibrillators. ${ }^{39,40}$

ECG changes associated with hyperkalemia can vary between patients, and even normal ECGs have been observed in patients who have severe hyperkalemia. The panel commented that some physicians may review an ECG and determine that the abnormalities are due to hyperkalemia while others may not. This is problematic, as there is no consensus on how to use ECGs in the diagnosis and treatment of hyperkalemia. The panel noted that a potential solution to this problem is the development of a diagnostic algorithm that eliminates ECG measurements as a precise indicator of hyperkalemia. The proposed diagnostic algorithm, developed by the panel, is shown in Figure 1.

The panel noted that a need exists for the development of a differentiation strategy for the identification and management of hyperkalemia in acute and chronic settings. The panel agreed that patiromer would be ideal in the chronic management setting; however, there are no clinical studies published supporting use in the emergency setting. Physicians in this setting must rely on calcium, insulin, bicarbonate, furosemide, or other treatments for patients presenting with emergent, lifethreatening hyperkalemia. Of note, approximately, 5 million doses of SPS are given yearly, despite the unfavorable safety and tolerability profile. ${ }^{25}$ Patiromer may present a better tolerability and safety option for these patients; however, neither SPS or patiromer are indicated for the management of emergent 
Expert Panel Recommendations for the Identification and Management of Hyperkalemia and Role of Patiromer in Patients with Chronic Kidney Disease and Heart Failure

FIGURE 1 Proposed Diagnostic Algorithm for Hyperkalemia $\left(\mathrm{K}^{+}>5.0 \mathrm{mEq} / \mathrm{L}\right)$

Treatment in the Acute Care Setting/Chronic Care

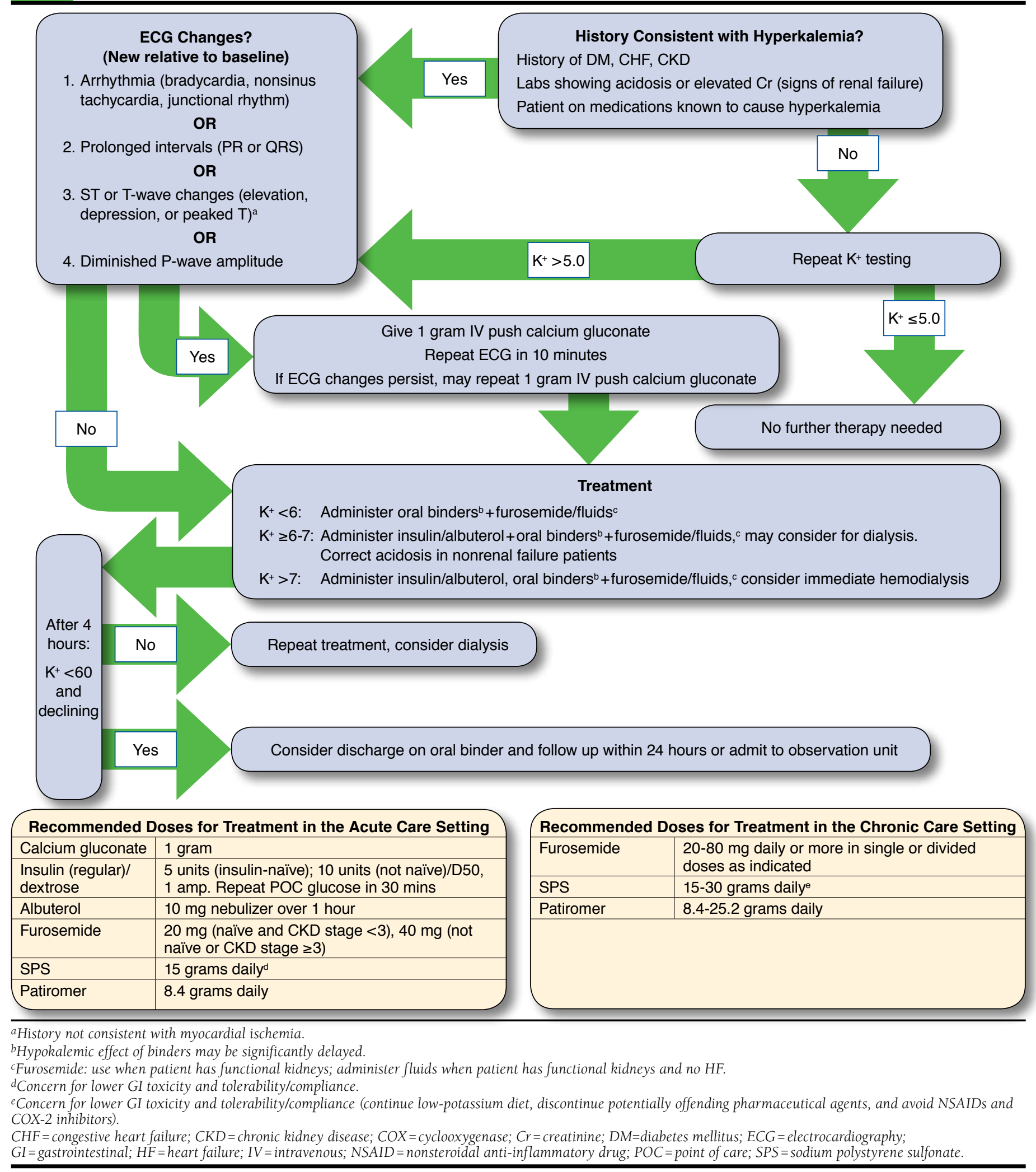


hyperkalemia, but both agents may be used to facilitate potassium lowering once emergent treatments have been initiated.

The panel also indicated that there is an educational deficit among patients and providers regarding patiromer use. Patient education about the correct use of patiromer is crucial, as many of these patients may be receiving treatment with patiromer and an RAAS inhibitor therapy concomitantly. This patient population must be counseled about the importance of treatment adherence. There is a risk of developing hyperkalemia with discontinuation of treatment with patiromer while continuing RAAS inhibitor therapy. Patients who discontinue treatment with an RAAS inhibitor may not receive the maximal clinical benefit of reduced morbidity and mortality with RAAS inhibitor treatment and should therefore be instructed to speak with their physician before discontinuing treatment with either therapy. ${ }^{12-14}$

Presently, many physicians are unfamiliar with the availability and administration of patiromer, and the panel suggested that a payer-, manufacturer-, or health care providerinitiated educational campaign may be beneficial in addressing this educational gap. Members of the panel indicated that the educational campaign should be targeted toward nephrologists, internal medicine, family medicine, and emergency medicine physicians, as they are the initial or first-line providers and treat the majority of these patients. Educational campaigns should also be directed toward cardiologists and physicians who work in the ED setting, as this is the setting in which most patients with hyperkalemia are treated and subsequently referred to primary care or a specialist. The panel felt that the clinical uptake of patiromer will be influenced by physicians' existing level of comfort with other therapies, the hesitancy to use new products prior to receiving adequate education or having experience with new-to-market agents, and the potential for beneficial outcomes among patients in their own practice.

\section{Future Implications/Considerations}

The panel agreed that patiromer appears to be a viable option for the management of hyperkalemia in patients with CKD and HF and in patients who experience chronic hyperkalemia. A number of issues still exist in the management of this patient population, including the lack of uniform treatment guidelines and consensus regarding the approach to treatment, the limited data demonstrating the safety and effectiveness of patiromer in the emergent setting, and the educational gap among patients and providers surrounding the availability and administration of this product. To address the lack of data supporting use in the acute setting, the panel recommended that a study be conducted in the ED setting to evaluate the role of patiromer as a treatment for life-threatening hyperkalemia. If such a trial is conducted, this would require changes to the hospital formulary in order for patients and prescribers to gain access to treatment with patiromer.

\section{Authors}

ZUBAID RAFIQUE, MD, FACEP, and W. FRANK PEACOCK, MD, FACEP, FACC, Baylor College of Medicine, Texas Medical Center, Houston. MATTHEW R. WEIR, MD, University of Maryland School of Medicine, Baltimore; MACAULAY ONUIGBO, MD, MSc, FWACP, FASN, MBA, Mayo Clinic Health System, Eau Claire, Wisconsin, and Mayo Clinic, Rochester, Minnesota; BERTRAM PITT, MD, University of Michigan School of Medicine, Ann Arbor; RICHARD LAFAYETTE, MD, Stanford University Medical Center, Stanford, California; and JAVED BUTLER, MD, Stony Brook University, Stony Brook, New York. MARIA LOPES, $M D$, and CAROLYN FARNUM, BS, Magellan Rx Management, Newport, Rhode Island.

CORRESPONDENCE: Servi Barrientos, Magellan Rx Management, 130 Bellevue Ave., Ste. 201, Newport, RI 02840. Tel.: 401.344.1020; E-mail: sbarrientos@magellanhealth.com.

\section{DISCLOSURES}

This panel discussion was funded by Relypsa and facilitated by Magellan Rx Management. Rafique is a principal investigator for Relypsa and serves as a consultant for Instrumentation Laboratory, Magellan Health, Relypsa, and ZS-Pharma. Butler serves as consultant for Amgen, AstraZeneca, Bayer, Boehringer Ingelheim, CardioCell, Janssen, Merck, Novartis, Relypsa, and ZS-Pharma. Lopes and Farnum are employed by Magellan Rx Management. Rafique designed the management protocol for this panel discussion and contributed to the writing and editing of this report document. The other authors report no conflicting interests. Relypsa is the manufacturer of Veltassa (patiromer)

\section{REFERENCES}

1. Garth D. Hyperkalemia in emergency medicine. Medscape. Updated September 2, 2016. Available at: http://emedicine.medscape.com/ article/766479-overview. Accessed April 18, 2017.

2. Einhorn LM, Zhan M, Hsu VD, et al. The frequency of hyperkalemia and its significance in chronic kidney disease. Arch Intern Med. 2009;169(12):1156-62.

3. An JN, Lee JP, Jeon HJ, et al. Severe hyperkalemia requiring hospitalization: predictors of mortality. Crit Care. 2012;16(6):R225.

4. Latts LM, Reaven NL, Funk SE, McGaughey KJ, Adamson RT. Hyperkalemia is prevalent in patients with cardiorenal comorbidities. Poster presented at: The International Society for Pharmacoeconomics and Outcomes Research (ISPOR) 20th Annual International Meeting; May 16-20, 2015; Philadelphia, PA.

5. Hollander-Rodriguez JC, Calvert JF Jr. Hyperkalemia. Am Fam Phys. 2006;73(2):283-90.

6. Drawz PE, Babineau DC, Rahman M. Metabolic complications in elderly adults with chronic kidney disease. J Am Geriatr Soc. 2012;60(2):310-315.

7. HCUP Nationwide Emergency Department Sample (NEDS). Healthcare Cost and Utilization Project (HCUP). 2014. Agency for Healthcare Research and Quality, Rockville, MD. Available at: www.hcup-us.ahrq.gov/nedsoverview.jsp. Accessed April 18, 2017. 


\section{Expert Panel Recommendations for the Identification and Management of Hyperkalemia and Role of Patiromer in Patients with Chronic Kidney Disease and Heart Failure}

8. HCUP National Inpatient Sample (NIS). Healthcare Cost and Utilization Project (HCUP). 2014. Agency for Healthcare Research and Quality, Rockville, MD. Available at: www.hcup-us.ahrq.gov/nisoverview.jsp. Accessed April 18, 2017.

9. Jain N, Kotla S, Little BB, et al. Predictors of hyperkalemia and death in patients with cardiac and renal disease. Am J Cardiol. 2012;109(10):1510-13.

10. Kovesdy CP. Management of hyperkalemia: an update for the internist. Am J Med. 2015;128(12):1281-87.

11. Reaven NR, Funk SE, Bakris GL. The economics of renoprotective therapy in advanced diabetic kidney disease. Am J Pharm Benefits. 2014;6(6):e169-e76.

12. Brenner BM, Cooper ME, de Zeeuw D, et al.; RENAAL Study Investigators. Effects of losartan on renal and cardiovascular outcomes in patients with type 2 diabetes and nephropathy. N Engl J Med. 2001;345(12):861-69.

13. Lewis EJ, Hunsicker LG, Clarke WR, et al.; Collaborative Study Group. Renoprotective effect of the angiotensin-receptor antagonist irbesartan in patients with nephropathy due to type 2 diabetes. N Engl J Med. 2001;345(12):851-60.

14. Yusuf S, Sleight P, Pogue J, et al.; The Heart Outcomes Prevention Evaluation Study Investigators. Effects of an angiotensin-converting-enzyme inhibitor, ramipril, on cardiovascular events in high-risk patients. N Engl J Med. 2000;342(3):145-53.

15. Epstein M, Reaven NL, Funk SE, McGaughey KJ, Oestreicher N, Knispel $\mathrm{J}$. Evaluation of the treatment gap between clinical guidelines and the utilization of renin-angiotensin-aldosterone system inhibitors. Am J Manag Care. 2015;21(11 Suppl):S212-S220.

16. Weir MR, Rolfe M. Potassium homeostasis and renin-angiotensin-aldosterone system inhibitors. Clin J Am Soc Nephrol. 2010;5(3):531-48.

17. Sadjadi SA, McMillan JI, Jaipaul N, Blakely P, Hline SS. A comparative study of the prevalence of hyperkalemia with the use of angiotensin-converting enzyme inhibitors versus angiotensin receptor blockers. Ther Clin Risk Manag. 2009;5(3):547-52.

18. Desai AS, Swedberg K, McMurray JJ, et al.; CHARM Program Investigators. Incidence and predictors of hyperkalemia in patients with heart failure: an analysis of the CHARM Program. J Am Coll Cardiol. 2007:50(20):1959-66.

19. Lehnhardt A, Kemper MJ. Pathogenesis, diagnosis and management of hyperkalemia. Pediatr Nephrol. 2011;26(3):377-84.

20. Ben Salem C, Badreddine A, Fathallah N, Slim R, Hmouda H. Druginduced hyperkalemia. Drug Saf. 2014;37(9):677-92.

21. Hagan AE, Farrington CA, Wall GC, Belz MM. Sodium polystyrene sulfonate for the treatment of acute hyperkalemia: a retrospective study. Clin Nephrol. 2016;85(1):38-43.

22. U.S. Food and Drug Administration. Significant dates in U.S. food and drug law history. December 19, 2014. Available at: http://www.fda.gov/ AboutFDA/WhatWeDo/History/Milestones/ucm128305.htm. Accessed April 18, 2017.

23. Lepage L, Dufour AC, Doiron J, et al. Randomized clinical trial of sodium polystyrene sulfonate for the treatment of mild hyperkalemia in CKD. Clin J Am Soc Nephrol. 2015;10(12):2136-42.

24. Chaitman M, Dixit D, Bridgeman MB. Potassium-binding agents for the clinical management of hyperkalemia. P.T. 2016;41(1):43-50.
25. Harel Z, Harel S, Shah PS, Wald R, Perl J, Bell CM. Gastrointestinal adverse events with sodium polystyrene sulfonate (Kayexalate) use: a systematic review. Am J Med. 2013;126(3):264.e9-24.

26. Sterns RH, Rojas M, Bernstein P, Chennupati S. Ion-exchange resins for the treatment of hyperkalemia: are they safe and effective? J Am Soc Nephrol. 2010;21(5):733-35.

27. Kayexalate (sodium polystyrene sulfonate). Sanofi-Aventis U.S 2009. Available at: https://www.accessdata.fda.gov/drugsatfda_docs/ label/2009/011287s022lbl.pdf. Accessed April 18, 2017.

28. Abraham SC, Bhagavan BS, Lee LA, Rashid A, Wu TT. Upper gastrointestinal tract injury in patients receiving kayexalate (sodium polystyrene sulfonate) in sorbitol: clinical, endoscopic, and histopathologic findings. Am J Surg Pathol. 2001;25(5):637-44.

29. U.S. Food and Drug Administration. FDA news release. FDA approves new drug to treat hyperkalemia. October 21, 2015. Available at: http://www. fda.gov/NewsEvents/Newsroom/PressAnnouncements/ucm468546.htm. Accessed April 18, 2017.

30. Veltassa (patiromer) for oral suspension. Relypsa. Updated November 2016. Available at: https://www.veltassa.com/pi.pdf. Accessed April 18, 2017.

31. Bushinsky DA, Williams GH, Pitt B, et al. Patiromer induced a rapid onset and sustained potassium lowering in patients with chronic kidney disease and hyperkalemia. Kidney Int. 2015;88(6):1427-33

32. Weir MR, Bakris GL, Bushinsky DA, et al. Patiromer in patients with kidney disease and hyperkalemia receiving RAAS inhibitors. N Engl J Med. 2015;372(3):211-21

33. Bakris GL, Pitt B, Weir MR, et al. Effect of patiromer on serum potassium levels in patients with hyperkalemia and diabetic kidney disease: the AMETHYST-DN randomized clinical trial. JAMA. 2015;314(2):151-61.

34. Pitt B, Anker SD, Bushinsky DA, Kitzman DW, Zannad F, Huang IZ; PEARL-HF Investigators. Evaluation of the efficacy and safety of RLY5016, a polymeric potassium binder, in a double-blind, placebo-controlled study in patients with chronic heart failure (the PEARL-HF) trial. Eur Heart J. 2011;32(7):820-28.

35. Sterns R, Grieff M, Bernstein P. Treatment of hyperkalemia: something old, something new. Kidney Int. 2016;89(3):546-54

36. Lederer E. Hyperkalemia. Medscape. January 11, 2016. Available at: http://emedicine.medscape.com/article/240903-overview. Accessed April 18, 2017.

37. Youssef M. First in a series on hyperkalemia: hyperkalemia, the sodium potassium pump and the heart. E-Journal of Cardiology Practice. Vol. 14, no. 11. May 24, 2016. Available at: http://www.escardio.org/ Journals/E-Journal-of-Cardiology-Practice/Volume-14/First-in-a-series-onHyperkalemia-Hyperkalemia-the-sodium-potassium-pump-and-the-heart. Accessed April 18, 2017.

38. Kiamanesh $O$, et al. Inappropriate shocks by subcutaneous implantable cardioverter-defibrillator due to T-wave oversensing in hyperkalemia leading to ventricular fibrillation. Heart Rhythm Case Reports. 2015;1(4):257-59.

39. Martindale J, deSouza IS. Managing pacemaker-related complications and malfunctions in the emergency department. Emerg Med Pract. 2014;16(9):1-21. Available at: http://www.slremeducation.org/wp-content/ uploads/2015/02/0914-Pacemakers.pdf. Accessed April 18, 2017.

40. Bortnik M, et al. Transient hyperkalemia-induced T-wave oversensing as a cause of inappropriate ICD charges. J Cardiol Cases. 2013;8(5):164-67.

41. Ben Salem C, Badreddine A, Fathallah N, et al. Drug-induced hyperkalemia. Drug Saf. 2014;37(9):677-92. 



\section{Supplement}

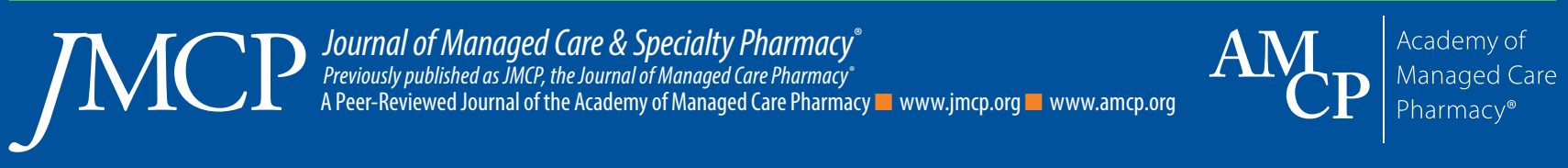

